\title{
Meaningful occupation clarified: Thoughts about the relationship between meaningful and psychologically rewarding occupations
}

\author{
Moses N Ikiugu, PhD OT (TWU, Denton, Texas) \\ Professor and Director of Research, Occupational Therapy. University of South Dakota
}

Ashley K Hoyme, MS OT (University of South Dakota)**

Occupational Therapist, Prairie Rehab

Brittany A Mueller, MS OT (University of South Dakota)**

Occupational Therapist, Kansas City Public Schools

\section{Rochelle R Reinke, MS OT (University of South Dakota)**}

Occupational Therapist, Outpatient Pediatric Clinic and Inpatient Acute Care, Grand Island, Nebraska

** Occupational therapy students at the University of South Dakota at the time of writing this article.

\begin{abstract}
A core assumption in occupational therapy is that participation in meaningful occupations is related to health and a sense of well-being. However, the exact nature of "meaningful occupation" is not clear. Many scholars seem to equate meaningful with psychologically rewarding occupations, whereby "psychologically rewarding" refers to an experience of absorption into the occupation and a positive mood at the time when the person is engaged in the occupation. In this paper, we argue that the two types of occupations are different. Meaningful occupation may not be immediately psychologically rewarding, but a psychologically rewarding occupation is always meaningful to the person performing it. Therapists should consider planning their therapeutic interventions in such a way that they use both types of occupations in order to optimise the benefits of therapy. Research is indicated to clarify the exact differences between the two types of occupations.
\end{abstract}

Key words: Meaningful occupation; psychologically rewarding occupation; mood; control; identity; transcendence

\section{INTRODUCTION}

Meaningful occupation is the core construct underlying the practice of occupational therapy. The profession has been historically based on the notion that occupation is important for basic well-being'. This basic premise is based on evidence from research which suggests that participation in meaningful occupations, including work, generally leads to increased feelings of well-being ${ }^{1,2,3}$. Occupational therapy scholars have gone as far as stating that those occupations that are not meaningful cannot be therapeutic ${ }^{4}$. However, the exact nature of meaningful occupation is difficult to grasp given the many definitions from multiple perspectives ${ }^{1,5}$.

Some scholars have argued that meaningful occupations are defined by doing things that are perceived as being right, important, and worthwhile, and that make them feel that they are competent and autonomous in the sense of having a choice regarding whether or not to do ${ }^{6,7,8,9}$. Others take an existential perspective and define meaningful occupations as those that engender a feeling that one's life has a purpose, that one has a worthwhile goal 
to pursue $e^{10,11}$. Still other scholars define meaningful occupations as those that make people experience a sense of flow ${ }^{12}$, by which is meant that participation in occupation produces a kind of "high" that comes from complete absorption in an activity that stretches one's creativity. According to Csikszentmihalyi ${ }^{12}$, such activities produce optimum satisfaction and happiness in life. Those who subscribe to this perspective equate meaningful occupations with absorption, satisfaction, and happiness. This hypothesis led some occupational therapists to hypothesise that meaningful occupations are healing precisely because they produce this sense of flow and in the process, activate the dopaminergic reward neural pathways of the brain including the ventral tegmental area [VTA], nucleus accumbens [NA], frontal cortex, anterior cingulate cortex $[A C C]$, amygdala, and the hippocampal formation ${ }^{13}$.

Using the principles of the mirror neuron theory ${ }^{14}$, Ikiugu et al. ${ }^{15}$ conducted a study to test this hypothesis. The mirror neuron theory is based on the observation in studies that neurons in the reward neural pathways respond as if one is engaged in an activity when he/she watches someone else performing the activity, or listens to a description of the activity being performed. Based on this theory, they hypothesised that if Gutman and Schindler's ${ }^{13}$ hypothesis was correct, the reward neuro-circuits (mesolimbic and mesocortical pathways) in the brain would be activated when individuals viewed themselves on video participating in self-selected meaningful occupations, or when they received verbal stimulation related to those meaningful occupations.

To test the above stated hypothesis, Ikiugu et al. ${ }^{15}$ had 10 study participants identify occupations that they perceived as meaningful to them (such as speaking on the phone with loved ones, doing woodwork, doing a favorite craft activity, etc.). They video-recorded the participants participating in the self-identified occupations. Then they performed Functional Magnetic Resonance Imaging (fMRI) scans of the participants under the following conditions: I) watching themselves on video while performing meaningful occupations; 2) watching themselves on video while engaging in rote exercises; 3 ) participating in word counting tasks related to their meaningful occupations; 4) participating in word counting tasks related to the meaningful occupations of other people; and 5) participating in word counting tasks related to things that are universally known to elicit activation of the human reward system (e.g., money, sex, and power).

Their findings indicated that: I) participants' reward neural pathways were not activated when they: a) watched themselves on video engaging in meaningful occupations; or b) participated in the word-counting task related to their meaningful occupations or the meaningful occupation of other people; however, 2) participants' reward neural circuits were activated when they engaged in the word counting task related to universal rewards, indicating that the experiment was sound and the lack of activation of the neural pathways as hypothesised when participants received stimulation related to their meaningful occupations was not due to inadequate design of the study. Therefore, their findings did not support the hypothesis that the reward neural pathways would be activated when individuals watched themselves participating in meaningful occupations or received verbal stimulation related to their meaningful occupations.

The above stated findings by lkiugu et al. ${ }^{15}$ led to the question of whether indeed meaningful occupations are the same as flow inducing (which in this paper we call momentarily psychologically rewarding) occupations, or the two types of occupations are different. In this paper, we argue that indeed meaningful occupations are not necessarily psychologically rewarding in the short-term, although they may produce a sense of health and well-being in the long term. We make a case that meaningful occupations are distinctly different from psychologically rewarding occupations, and although psychologically rewarding occupations are always meaningful, the other way around is not always the case. We suggest that occupational therapists may want to think about how they combine meaningful and psychologically rewarding occupations in therapy in order to facilitate a state of health and well-being both in the short-term and the long term.

\section{THE DIFFERENCES BETWEEN MEANINGFUL AND PSYCHOLOGICALLY REWARDING OCCUPATIONS}

\section{Characteristics of Meaningful Occupations}

As mentioned earlier, there is no consensus in the literature regarding how to define meaningful occupations. Some define such occupations existentially by suggesting that they provide individuals with a sense of meaningful existence ${ }^{5,16,17}$. Others see them as constituting activities that a person perceives as important in his/ her life. For example, Trombly ${ }^{18}$ defined the meaning of occupation as deriving from:

“... a person's sense of the importance of participating in certain occupations or performing in a particular manner; or from the person's estimate of reward in terms of success or pleasure; or perhaps from a threat of bad consequences if the occupation is not engaged in"18:517.

This definition seems to combine goal-orientedness and happiness as the determinants of a meaningful occupation. The problem of lack of clarity in regard to what exactly constitutes meaningful occupations has continued in the occupational therapy literature as argued by Hammell in the following statement:

"Occupational therapy theory has demonstrated a clear difficulty with differentiating between the concepts purposeful and meaningful, sometimes using the terms interchangeably and tending to extol the notion of meaningful occupation while focusing instead on purposeful, goaloriented, socially sanctioned use of time and energy in doing ..."19:297.

In recent times, there has been increasing consensus that meaningful occupations, among other things, provide people with a sense of control, identity, connection with other people, selftranscendence (in the sense of demonstrating caring for a person or a thing other than oneself), competence, self-expression, and connection to a larger reality than oneself ${ }^{5,20,21}$. However, as Ikiugu and Pollard ${ }^{5}$ argued, while meaningful occupations may provide one with a sense of purpose in life, a sense of transcendence, etc., they may not always be experienced as always producing a sense of flow. In fact, sometimes, they can be dreary, or they may even lead to experiences of pain and suffering. For example, people who have transformed the world, such as Martin Luther King Jr., Nelson Mandela, Mahatma Gandhi, and many others may by all accounts be viewed as having been engaged in occupations that were highly meaningful as they pursued their causes. However, all of them also experienced much suffering including beatings, incarceration for many years, risk of death (or even death in the case of Martin Luther King Jr.), etc.

Even meaningful occupations of individuals living average lives are not always imbued with happiness. Consider for example a student studying for an exam. For the student, studying may be experienced as dreary, even though it is a very meaningful occupational activity because it would lead to success in the student role. The experience of high that is associated with flow may not be there when one is studying although it may come later when the student receives the news that he/she did very well on the exam. The point is that a meaningful occupation may not be necessarily psychologically rewarding (by "psychologically rewarding" meaning an occupation producing a sense of flow characterised by absorption, happiness, and satisfaction) in the moment that one is participating in it.

\section{Characteristics of a Psychologically Rewarding Occupation}

Even though occupational therapists have argued that meaningful occupations activate the reward neural pathways and thus contribute to a decrease in stress and an increase in the sense of well-being (thus suggesting that the psychological reward is the healing component of occupations) ${ }^{13}$, the nature of psychologically rewarding occupations has not been explored much in occupational therapy and occupational science literature even though it has been discussed in other professions. For example, Trenberth ${ }^{22}$ completed 
a systematic review of literature in counseling psychology in which the therapeutic benefits of leisure activities were investigated. Her review revealed that leisure occupations seem to be effective in reducing stress. She concluded that leisure participation contributed to physical, social, and psychological sense of well-being by helping people achieve transcendence, sense of control and selfdetermination (which seems to be similar to the characteristics of meaningful occupations as described earlier). They also found that leisure activities can be effective in inducing positive mood (which we are suggesting is an indicator of a "psychologically rewarding" experience). In this sense, leisure occupations seem to be both meaningful and psychologically rewarding.

In another study, Cohen and Shamus ${ }^{23}$ reviewed literature in which the effect of physical activity, in particular exercise, on psychological well-being (positive mood) was investigated. Their review indicated that moderate aerobic exercise performed for at least 20 minutes every day produced significant positive psychological benefits. Such activities included swimming, biking, and yoga. However, they found that highly competitive activities such as sports may actually produce negative emotional states such as anger, anxiety, and stress. Similarly, Poole et al..$^{24}$ found that physical activity was associated with a positive affect among women. Thus, literature seems to indicate that physical activity is associated with positive mood (see also ${ }^{25,26,27}$ ).

Based on the above discussion, it seems that occupations that produce positive mood or flow (are psychologically rewarding as per our definition) are those that are discretionary (leisure occupations, which we assume are fun since they are freely chosen) and physical in nature. However, it is important to note that not much research investigating the characteristics of occupations that are psychologically rewarding has been conducted by occupational therapists. Much of this research seems to have been generated by psychologists and psychological counselors. Clearly, there is a need for extensive research by occupational therapists to investigate the nature of psychologically rewarding occupations.

\section{Similarities and Differences between Meaningful and Psychologically Rewarding Occupations}

Based on the above discussion the characteristics that make meaningful and psychologically rewarding occupations similar as well as different are listed in Table $I$. be done to generate further data to clarify the differences between meaningful and psychologically rewarding occupations, particularly from an occupational therapy perspective.

\section{Implications for Practice}

If our hypothesis that meaningful occupations are essentially different from psychologically rewarding occupations is correct, it seems that occupational therapists may find it useful to help their clients develop goals that lead to eventual habitual participation in meaningful occupations (i.e., participation in occupations that provide a sense of control and self-determination and a chance for self-transcendence). However, in therapeutic sessions, they should also incorporate occupations that elicit positive mood (such as leisure, physically stimulating, and mentally stimulating occupations) as therapeutic media. The suggested therapeutic strategy is illustrated in the case below.

\section{Case:}

Ben (not real name) is a 54-year-old man who has sustained a rightside Cerebrovascular Accident (CVA). He is receiving outpatient occupational therapy services with the goal of increasing independence in basic Activities of Daily Living (ADLs). Initial evaluation indicates that Ben is able to ambulate using a cane. His left arm is in a sling. He informed the therapist that he wanted to be independent in self-dressing so that he could manage his pair of jeans and use the restroom independently. He perceived the need for help to use the restroom as demeaning and as being an attack on his self-image.

As therapy continued, Ben revealed to the therapist that it was also important for him to get back to work. He stated that work provided him with a purpose because he was able to provide for his family, which was important for his identity as a man. He also wanted to have more control over his life by being independent in basic ADLs. Evaluation of his work skills at his job site indicated that he had adequate mobility to get around the work facility. The discovery that he could easily adapt to his work environment seemed to lift his mood dramatically. He excitedly socialised with his co-workers during the session. This was the most excited that the therapist had seen Ben since she started working with him. He made jokes, teased the therapists, and was constantly smiling. Over the next few weeks, the therapist worked with Ben to help him transition to part-time work while continuing with therapy. This

Table I: Comparisons of the Characteristics of Meaningful Occupations with those of Psychologically Rewarding Occupations

\begin{tabular}{|l|l|}
\hline Meaningful occupations are those that provide a means for: & $\begin{array}{l}\text { Psychologically rewarding occupations are those that provide a } \\
\text { means for: }\end{array}$ \\
\hline Experiencing a sense of control & Experiencing a sense of control and self-determination \\
\hline Identity & Self-transcendence \\
\hline Connection with other people & Experiencing positive mood \\
\hline Self-transcendence & Physical stimulation \\
\hline Competence & Fun \\
\hline Self-expression & \\
\hline Connection to a larger reality than oneself & \\
\hline Note: The text in bold type indicates characteristics that are common to both meaningful and psychologically rewarding occupations. \\
\hline
\end{tabular}

As can be seen in Table I, both meaningful and psychologically rewarding occupations provide individuals with a sense of control and self-determination as well as an opportunity for self-transcendence. However, based on the literature reviewed, psychologically rewarding occupations have the following three unique characteristics: eliciting positive mood; providing mental or physical stimulation (they provide mental stimulation by stretching one's imagination); and they are fun. The above analysis supports our original postulation that psychologically rewarding occupations are essentially meaningful, but meaningful occupations may not necessarily be psychologically rewarding (at least at the moment when they are being performed). Obviously, more work needs to was a transformational moment in his therapy. He became more absorbed in therapeutic tasks, and his wife reported that he was doing better in ADLs and social activities at home.

Following is a brief analysis of the use of meaningful and psychologically rewarding occupations in Ben's therapy. Obviously, the therapist used a combination of occupational therapy theoretical conceptual practice models such as the Canadian Model of Occupational Performance, Biomechanical model, etc. to guide therapy. However, in this paper, we will only focus on how she used meaningful and psychologically rewarding occupations as media.

First, the therapist was able to identify meaningful occupations (occupations that provided Ben with a sense of control, identity, 
autonomy, and self-transcendence). These were: returning to work (to restore his identity as a provider for his family); and increased independence in basic ADLs (to restore his dignity as a man who could take care of himself). These became the long terms goals towards which Ben worked with the help of the therapist. However, during therapy, occupations that were psychologically rewarding were used in order to provide motivation for Ben. An example of such occupations included socialising with friends at work during the work evaluation session. One can argue that what was psychologically rewarding during this instance was actually being at the work-place rather than social participation. However, considering his interaction with co-workers and how this interaction seemed to excite him, a case can be made that one of the important benefits of work for Ben might have been the social participation that it afforded. Thus, social participation in and unto itself was probably psychologically rewarding for him.

Other psychologically rewarding occupations that the therapist could have used during therapy sessions could have included social leisure activities (such as playing card games, bingo, etc.), since clearly, Ben seemed to enjoy social participation activities. Combining meaningful occupations (activities related to his goal of being independent in self-care and returning to work) and psychologically rewarding occupations (social leisure participation) would have optimized therapeutic benefits for Ben, providing healing in the moment while ensuring working towards sustained meaningful existence for a sense of well-being in the long term.

\section{CONCLUSION}

Although occupational therapy is based on the idea that meaningful occupations are related to health and a sense of well-being, the exact nature of such occupations is not quite well understood. Sometimes, meaningful occupation is understood to be synonymous with psychologically rewarding occupation (by psychologically rewarding meaning inducing positive mood or a sense of flow at the moment when the occupation is performed). In this paper, we argued that meaningful and psychologically rewarding occupations are different. We found that there are some characteristics that are common to both. Both types of occupation are associated with a sense of control and self-determination, as well as self-transcendence. However, positive mood is an effect produced exclusively by psychologically rewarding occupations. We suggested that as occupational therapists plan therapy, they should consider participation in meaningful occupations as the long-term goal for their clients. However, they should incorporate psychologically rewarding occupations as media in their daily therapeutic interventions. Research is indicated to investigate these characteristics of occupations in depth.

\section{REFERENCES}

I. Argentzell, E., Hakansson, C., \& Eklund, M. Experience of meaning in everyday occupations among unemployed people with severe mental illness. Scandinavian Journal of Occupational Therapy, 20 I2; 19: 49-58.

2. Ivtzana, I., Sorensena, E., \& Halonen, S. The Effect of occupational meaningfulness onoccupational commitment. International Journal of Psychological Research, 2013; 6(2): I5-23.

3. Mclntyre, G., \& Howie, L. Adapting to widowhood through meaningful occupations: A case study. Scandinavian Journal of Occupational Therapy, 2002; 9: 54-62.

4. Bigelius, U., Eklund, M., \& Erlandsson, L. The value and meaning of an instrumental occupation performed in a clinical setting. Scandinavian Journal of Occupational Therapy, 2010; 17 : 4-9.

5. Ikiugu, M. N., \& Pollard, N. (In press). Meaningful Living across the Lifespan: Occupation-based intervention strategies for occupational therapists and scientists. London, UK: Whiting \& Birch.

6. Hvalsoe B, Josephsson S. Characteristics of meaningful occupations from the perspective of mentally ill people. Scandinavian Journal of Occupational Therapy, 2003; 10: 61-71.

7. Christiansen $\mathrm{CH}$. Defining lives: Occupation as identity: An essay on competence, coherence, and the creation of meaning. The American Journal of Occupational Therapy, 1999; 53: 547-558.

8. Hammell KW. Dimensions of meaning in the occupations of daily life. Canadian Journal of Occupational Therapy, 2004; 7I: 296-305.

9. Majnemar A. Balancing the boat: Enabling and ocean of possibilities. Canadian Journal of Occupational Therapy, 2010; 77: 198-208.

10. Yalom, CP. Existential psychotherapy. New York: Basic Books; 1981.

II. Chen, CP. On exploring meanings: combining humanistic and career psychology theories in counseling. Counselling Psychology Quarterly, 2002; 1469-3674.

12. Csikszentmihalyi, M. Finding flow: The psychology of engagement with everyday life. New York: Basic Books, 1997.

13. Gutman S and Schindler V. The neurological basis of occupation. Occupational Therapy International, 2007; I4(2): 7 I-85.

14. Kohler E, Keysers C, Umiltà MA, Fogassi L, Gallese V and Rizzolatti G. Hearing sounds, understanding actions: Action representation in mirror neurons. Science, 2002; 297(5582): 846.

15. Ikiugu M, Baugh LA, Cleveringa L, Korth B and Skinner M. The effect of participation in meaningful occupations on brain activity as observed on functional magnetic resonance imaging (fMRI). Unpublished manuscript, University of South Dakota, Occupational Therapy Department, Vermillion, South Dakota, 2013.

16. Ikiugu MN. Meaningfulness of occupations as an occupational-lifetrajectory attractor. Journal of Occupational Science, 2005; 12(2): 102-109.

17. Ikiugu, M. N. and Rosso, H. M. Understanding the occupational human being as a complex, dynamical, adaptive system. Occupational Therapy in Health Care, 2006; 19(4): 43-65.

18. Trombly, C. A. Eleanor Clark Slagle Lecture - Occupation: Purposefulness and meaningfulness as therapeutic mechanisms. American Journal of Occupational Therapy, 1995; 49: 960-972.

19. Hammell, K. W. (2004). Dimensions of meaning in the occupations of daily life. Canadian Journal of Occupational Therapy; 71: 296-305.

20. Ikiugu M, Polland N, Cross A, Willer M, Everson J and Stockland J. Meaning making through occupations and occupational roles: $A$ heuristic study of worker-writer histories. British Journal of Occupational Therapy, 2012; 75(6): 289-295.

21. Perruzza, N. and Kinsella, E. Creative arts occupations in therapeutic practice: A review of the literature. British Journal of Occupational Therapy, 2010; 73(6): 26I-268.

22. Trenberth, $L$. The role, nature and purpose of leisure and its contribution to individual development and well-being. British Journal of Guidance and Counselling, 2005; 33(I): I-6.

23. Cohen, G. E. and Shamus, E. Depressed, low self-esteem: What can exercise do for you? Internet Journal of Allied Health Sciences and Practice, 2009; 7(2): I-5.

24. Poole, L., Steptoe, A., Wawrzyniak, A. J., Bostock, S., Mitchell, E. S. and Hamer, M. Associations of objectively measured physical activity with daily mood ratings and psychophysiological stress responses in women. Psychophysiology, 20 I I; 48: I I65-II 72.

25. Apolzan, J. W., Flynn, M. G., McFarlin, B. K. and Campbell, W. W. Age and physical activity status effects on appetite and mood state in older humans. Applied Physiology, Nutrition, and Metabolism, 2009; 34: 203-211.

26. Childs, E. and de Wit, H. Regular exercise is associated with emotional resilience to acute stress in healthy adults. Frontiers in Physiology, 20I4; 5(16I): I-7.

27. Wiles, N. J., Haase, A. M., Lawlor, D. A., Ness, A. and Lewis, G. Physical activity and depression in adolescents: Cross-sectional findings from the ALSPAC cohort. Social Psychiatry and Psychiatric Epidemiology, 2012; 47: 1023-1033.

http://dx.doi.org/ I 0. I 7 I 59/23 I 0-3833/20 I 5/v45no I a8

Corresponding Author

Moses Nguu Ikiugu

Moses.lkiugu@usd.edu 